\title{
Article \\ The Effects of Display Parameters and Devices on Spatial Ability Test Times
}

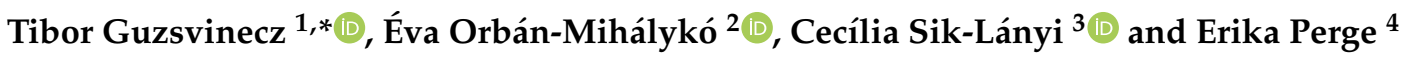 \\ 1 Department of Information Technology and Its Applications, University of Pannonia, \\ 8900 Zalaegerszeg, Hungary \\ 2 Department of Mathematics, University of Pannonia, 8200 Veszprem, Hungary; orbane@almos.uni-pannon.hu \\ 3 Department of Electrical Engineering and Information Systems, University of Pannonia, \\ 8200 Veszprem, Hungary; lanyi@almos.uni-pannon.hu \\ 4 Department of Basic Technical Studies, University of Debrecen, 4028 Debrecen, Hungary; \\ perge@eng.unideb.hu \\ * Correspondence: guzsvinecz.tibor@zek.uni-pannon.hu
}

check for updates

Citation: Guzsvinecz, T.; Orbán-Mihálykó, É.; Sik-Lányi, C.; Perge, E. The Effects of Display Parameters and Devices on Spatial Ability Test Times. Appl. Sci. 2022, 12, 1312. https://doi.org/10.3390/ app12031312

Academic Editor: Jozsef Katona

Received: 5 December 2021

Accepted: 24 January 2022

Published: 26 January 2022

Publisher's Note: MDPI stays neutral with regard to jurisdictional claims in published maps and institutional affiliations.

Copyright: () 2022 by the authors Licensee MDPI, Basel, Switzerland. This article is an open access article distributed under the terms and conditions of the Creative Commons Attribution (CC BY) license (https:// creativecommons.org/licenses/by/ $4.0 /)$.

\begin{abstract}
The effects of display parameters and devices are examined on spatial ability test times in virtual environments. Before the investigation, completion times of 240 and 61 students were measured, using an LG desktop display and the Gear VR, respectively. The virtual environment also logged the following randomized display parameters: virtual camera type, field of view, rotation, contrast ratio, whether shadows are turned on, and the used display device. The completion times were analyzed using regression analysis methods. Except for the virtual camera type, every factor has a significant influence on the test completion times. After grouping the remaining factors into pairs, triplets, quartets, and quintets, the following can be concluded: the combination of $75^{\circ}$ field of view, $45^{\circ}$ camera rotation, and 3:1 contrast ratio has the largest increase in completion times with an estimate of $420.88 \mathrm{~s}$ - even when this combination is in-side a quartet or a quintet. Consequently, significant decreases in completion times exist up to variable quartets (the largest being $-106.29 \mathrm{~s}$ on average), however, the significance disappears among variable quintets. The occurrences of factors were also investigated: an undefined field of view, a $0^{\circ}$ camera rotation, the Gear VR, a 7:1 contrast ratio, and turned-on shadows are the factors that occur in most significant combinations. These are the factors that often and significantly influence completion times.
\end{abstract}

Keywords: cognitive skills; desktop display; Gear VR; human-computer interaction; mental rotation; spatial ability; virtual reality

\section{Introduction}

Since well-developed spatial skills are necessary for several jobs, mainly for those that are related to engineering [1], they are considered to be essential in the present day. Fortunately, as they are cognitive skills, they can be improved through time [2]. It is imperative that training of spatial skills should be included in the studies of engineering students [3]. Through the years, several paper-based geometric problems that can improve spatial ability were created in the literature. In this paper, three such tests are focused on: the Mental Rotation Test (MRT) [4], Mental Cutting Test (MCT) [5], and the Purdue Spatial Visualization Test (PSVT) [6].

Although their numbers are still scarce, new versions of these spatial ability improving tests are recreated in virtual or augmented environments [7-10], and some even include gamification elements [11,12]. Building such virtual/augmented versions of these tests is quite complex: according to Burdea and Coiffet, a virtual system is created of five various parts: software/database(s), the VR engine behind it, tasks, I/O devices, and the users themselves [13]. Due to its complexity, the design of virtual environments can influence 
human-computer interaction because users can be immersed and human-computer interfaces can be redefined $[14,15]$. There is no perfect human-computer interaction for virtual reality applications because the interaction type varies from application to application [16]

As can be observed, design is quite important in virtual environments. According to Cutmore et al., users perform better in dynamic environments [17], while the study of Cidota et al. concludes that the blur, and fade effects as well as "standard environments" can positively influence users [18]. Using a head-mounted display can also enhance the performance of users in virtual reality [19], and user characteristics can also influence the results on tests [20], even their completion times as well [21]. However, distances from objects are typically underestimated in virtual environments [22], however binocular disparity and a carefully adjusted camera should be provided to increase the presence of the users [23]. This means that with a carefully designed virtual environment, spatial skills can be improved [24-28].

Among others, investigation of human-computer interaction in virtual worlds is part of the Cognitive InfoCommunications (CogInfoCom) environment [29-34] which was used for this and the authors' previous studies: spatial skills are also investigated in it [11,12,35], and the optimal user-centric virtual environment- to enhance the spatial skills of userswas also found [36].

Based on the literature and previous research, the display parameters and devices are in interaction with the various users: every factor has some influence on the correct answers reached on the spatial ability tests. Even the characteristics of users affect current answers [9,19,37], and completion times [21]. However, what about the display parameters? Do they affect test completion times?

To find an answer to this question, a previously developed spatial ability measuring virtual environment was used [38]. While the application logs user results and information about the tests, display parameters-such as the virtual camera type, its field of view (FoV), rotation, contrast ratio, and the existence of shadows-can be controlled in the application. For the measurements, participants either used a desktop display or the Gear VR head-mounted display. 240 participants tested with the former, and 61 with the latter. Their completion times were evaluated using linear regression analysis. According to the results, a combination of $75^{\circ} \mathrm{FoV}, 45^{\circ}$ camera rotation, and 3:1 contrast ratio has the largest increase in completion times-even when this combination is inside a quartet or a quintet. Consequently, significant decreases in completion times exist up to variable quartets and the significance disappears among variable quintets.

The structure of this study is the following: research questions (RQs) and hypotheses (Hs) are presented in Section 2; the materials and methods are detailed in Section 3; the results are shown in Section 4, while they are discussed in Section 5. Conclusions are made in Section 6.

\section{Research Questions and Hypotheses}

To investigate the interaction between human and machine, test times were in focus during this research. As the investigation focuses on the influence of display parameters and devices on test times, two RQs and Hs were formed. The RQs are the following:

- RQ1: Are test times influenced by various display parameters and devices? Is there an interaction between them?

- $\quad \mathrm{RQ2}$ : Which combination of these factors results in either the smallest or the largest test times? The authors try to recognize the best and the worst combinations.

After the RQs were formed, the same number of Hs was also formed. To make complete testing hypotheses, first, the null hypotheses are phrased, then the alternative hypotheses are phrased. These are the following:

Hypothesis 1 (H1). No significant influences on completion times exist due to various display parameters and devices, opposite to significant influences on completion times exist due to various display parameters and devices. 
Hypothesis 2 (H2). The smallest and the largest completion times are not significantly influenced by these factors, opposite to the smallest and the largest completion times are significantly influenced by these factors.

\section{Materials and Methods}

This section is split into three subsections: the development, data collection, and lastly, data analysis. These can be found in Sections 3.1-3.3, respectively.

\subsection{Development}

In 2019 a spatial ability measuring application was developed using the Unity game engine to answer the RQs and Hs. This application is compatible with newer Windows $(7+)$ and Android (7.0+) versions. The latter version was required to create an immersive virtual reality experience: it can be used with the Samsung Gear VR SM-R322 head-mounted display [39], while a Samsung S6 Edge+ smartphone was placed into it [40].

Two differences exist among the two versions: interaction and level of immersion. Naturally, when the Gear VR is used, users feel that they are "inside" the virtual environment, thus the level of immersion is increased. It is not possible to move; only the rotation of their head is possible. Regarding interaction, users have to look at objects and tap the touchpad on the right side of the Gear VR to select objects, while when using the desktop display, objects can be selected by pressing the left mouse button or corresponding keys on the keyboard (1-4 or 1-5 depending on the test types).

At the moment, there are three types of tests in the application: the MRT, MCT, and PSVT test types, although the Heinrich Spatial Visualization Test [41] is in process of being implemented in it. The MRT, MCT, and PSVT test types are shown in Figure 1.

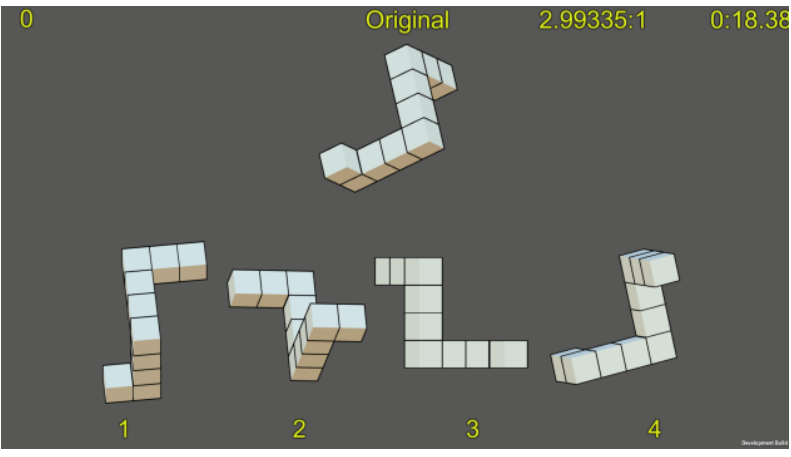

(a)

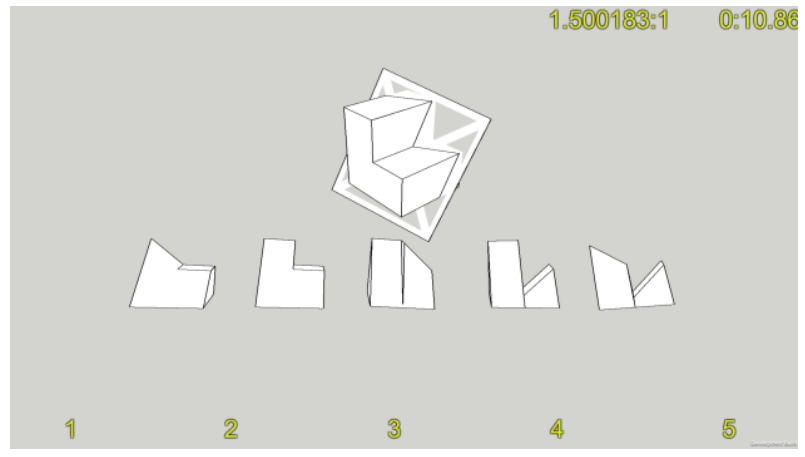

(b)

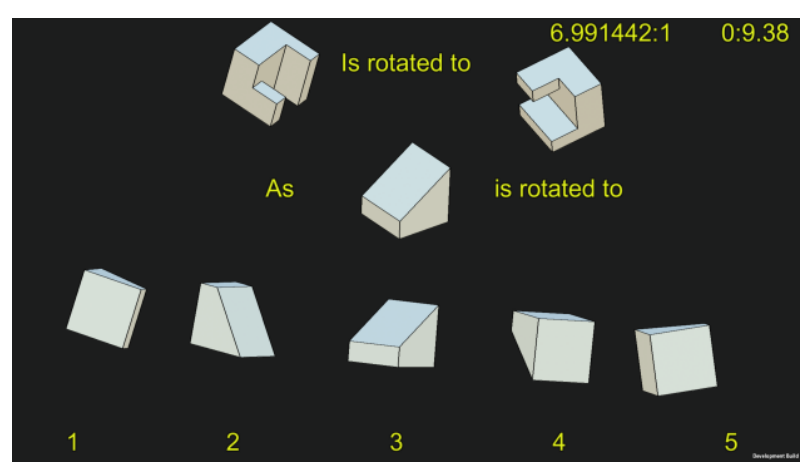

(c)

Figure 1. The various test types: (a) MRT test with an orthographic camera, 3:1 contrast ratio, no rotation, and shadows turned on; (b) MCT test with a perspective camera, $60^{\circ} \mathrm{FoV}, 1.5: 1$ contrast ratio, no rotation, and shadows turned off; (c) PSVT test with an orthographic camera, 7:1 contrast ratio, $15^{\circ}$ camera rotation, and shadows turned on. 


\subsection{Data Collection}

Both the University of Pannonia and University Debrecen were the sites of measurements. The spatial skills of 61 students were measured using the Gear VR version at the former university, and 240 students participated using the LG 20M37A (19.5") desktop display at the latter university [42]. Information technology (IT) and non-IT students used the Gear VR version, while architectural/civil engineering and mechanical engineering students used the desktop display version.

The tests were constructed as the following: students had to solve 10 problems of each test type in sequential order. After they finished, they could rest, if they wanted. Then, they had to solve another 10 problems of each test type. Afterward, they could rest, and then, another 10 problems of each test type had to be solved. The reason why these tests had to be solved three times is that the display parameters were using a randomization technique: two or three display parameters were randomized before starting each test type. While this could result in smaller sample sizes, a large number of results could be achieved with it in the end. It should be noted that both the problems and their answers were also randomized, thus eliminating the possibility that the students remember them.

Since one Gear VR device was available at the University of Pannonia, students had to come sequentially for the measurements. As each person took around 30-50 min to complete all tests, 3 weeks were needed to measure the spatial skills of everyone. Testing was easier at the University of Debrecen: a computer laboratory with a capacity of 20 people was used. Therefore, the students were grouped into 20 groups. All students were informed of the tests, and every one of them gave oral consent before the measurements commenced, although their names were not recorded. It is impossible to identify them based on the logged data alone.

The application logs the following information about the students while respecting their anonymity: their age, gender, primary hand, what their major is, and their number of university years. These previous user characteristics are not focused on in this study. It also logs the test type, number of correct answers, and completion times. Naturally, the display parameters are also logged: the contrast ratio, whether there are shadows in the scene, virtual camera type, its rotation, and its field of view. It was not necessary to log the various display devices because each version logs the information into a different .csv file. Therefore, it is possible to identify them later.

\subsection{Data Analysis}

2709 lines of data were collected during the measurements. Each line contained the logged information presented in the previous subsection. The data was analyzed in the statistical program package R [43]. Since the goal was to clarify the factors' influences on test completion times, regression methods were used [44]. During the investigation, the influences of the factors were examined one by one, in pairs, in triplets, in quartets, and a quintet. The results of the investigation are presented in the following section.

\section{Results}

The completion times are investigated in this section. The largest time is $1168.43 \mathrm{~s}$, while the smallest is $7.9 \mathrm{~s}$ (although it is impossible to solve 10 spatial ability problems in this small time). The mean of all test times is $200.388 \mathrm{~s}$, while the dispersion is $123.279 \mathrm{~s}$. Before the analysis, the distribution of completion times is investigated. To do so, the Kolmogorov-Smirnov test was used, and its results prove that the data does not follow a Gauss-distribution ( $p$-value $<2.2 \times 10^{-16}$ ).

To analyze these test times, the effect of display parameters and devices are examined on them: the possible factors are investigated by one in the first subsection, while they are investigated in pairs, triplets, quartets, and a quintet in the second, third, fourth, and fifth in the following subsections. 


\subsection{The Effect of Each Factor}

In this section, each factor (camera type, its FoV, rotation, contrast ratio, a display device, and whether shadows are turned on) was investigated with regression analysis. This means that each factor was compared to the basis of the variable, its coefficient is named Intercept in each case and the level itself Intercept Level. The results of every significant comparison are presented with 95\% confidence intervals (CIs) in Figure 2. It should be noted that confidence intervals can be visualized well: it is possible to observe the effects of variables, but if the confidence interval belonging to a non-basis level variable reaches zero, then there is no significant effect of this level on the test completion related to the basis.

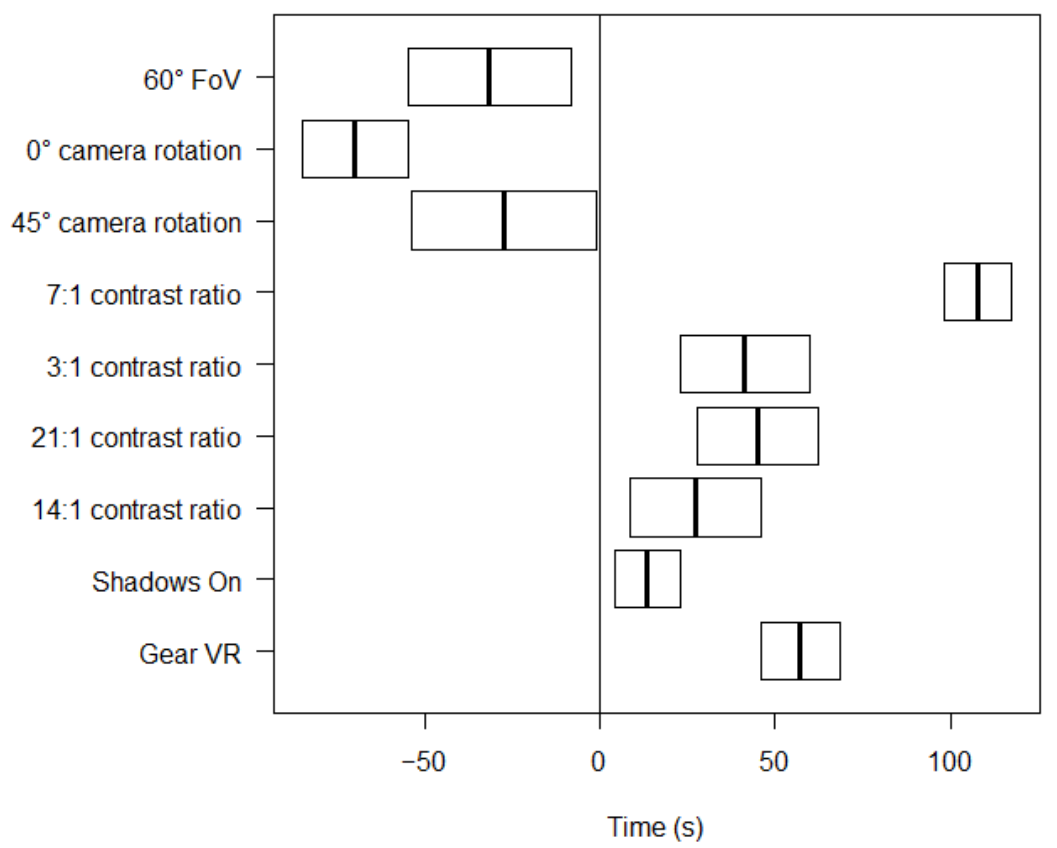

Figure 2. 95\% CIs of each significant factor.

First, the effect of the camera type was analyzed. It has to be noted that a virtual camera has two types: orthogonal and perspective. The former uses orthographic projection, while the latter is similar to the human eye. 1291 tests were conducted with the former and 1418 with the latter. The former also was the Intercept variable with an estimate of $201.081 \mathrm{~s}$. According to the results, the camera type does not significantly affect the completion times ( $p$-value $=0.78)$. Therefore, the camera type was omitted from further analysis.

Next, the influence of camera FoVs was examined. This factor had 5 levels in this study: $45^{\circ}, 60^{\circ}, 75^{\circ}, 90^{\circ}$ and undefined. The latter also means that an orthogonal camera was used since the FoV is undefined in that case. 1049, 120, 134, 115, and 1291 tests were done with all these levels, respectively. Here, the Intercept level was $45^{\circ}$ with an estimate of $205.586 \mathrm{~s}$. As shown by the results of the regression analysis, only the $60^{\circ} \mathrm{FoV}$ has a significant effect ( $p$-value $=0.00788)$ : the times are decreased in this case, on average. Out of the remaining levels, $90^{\circ} \mathrm{FoV}$ was the closest to being significant $(p$-value $=0.10340)$. These insignificant factors also decreased the completion times, albeit slightly.

Afterward, the camera rotation was investigated. 7 levels existed in this case: $-45^{\circ}$, $-30^{\circ},-15^{\circ}, 0^{\circ}, 15^{\circ}, 30^{\circ}$, and $45^{\circ} .294,294,106,1251,312,313$, and 139 tests were done with these levels, respectively. The Intercept level was $-15^{\circ}$ with an estimate of $236.1102 \mathrm{~s}$. As can be seen, two variables have significant effects which decrease completion times: $0^{\circ}$ $\left(p\right.$-value $\left.<2 \times 10^{-16}\right)$, and $-45^{\circ}(p$-value $=0.044)$. This means that in most cases, significantly smaller test completion times can be reached without camera rotation. 
The following variable to examine was the contrast ratio: there were 5 levels in this case: 1.5:1, 14:1, 21:1, 3:1, and 7:1. Respectively, the number of tests was 1066, 164, 191, 167, and 1121. 1.5:1 was the Intercept level with an estimate of $148.378 \mathrm{~s}$. As can be seen, every level has a significant influence, and each increases the completion times. The significances are the following: 3:1 $\left(p\right.$-value $\left.=1.13 \times 10^{-5}\right), 7: 1\left(p\right.$-value $\left.<2 \times 10^{-16}\right), 14: 1$ $(p$-value $=0.00391)$, and 21:1 $\left(p\right.$-value $\left.=4.45 \times 10^{-7}\right)$. The best case is contrast ratio 7:1. It means, that the contrast should be increased to a certain level, but if it is too strong, its effect decreases.

Next, the existence of shadows in the scene was assessed. Therefore, there were two levels: shadows are turned on (1414 tests), and shadows are turned off (1295 tests). The latter was the Intercept level with an estimate of $193.355 \mathrm{~s}$. According to the results, when shadows are turned on, the completion times are significantly increased ( $p$-value $=0.00447$ ). It means, that the lack of shadow is better. Its existence could be confusing.

Lastly, the used display device was assessed. Similarly, there were two levels in this case: desktop display (2160 tests) and the Gear VR (549 tests). The former was the Intercept level with an estimate of $188.784 \mathrm{~s}$. Due to the results of the regression analysis, it can be concluded that the use of the Gear VR significantly increased the completion times ( $p$-value $\left.<2 \times 10^{-16}\right)$. It means that people need more time in immersive circumstances, which can be explained by the unusual conditions.

\subsection{The Effect of Factor Pairs}

After the factors (variables) were analyzed one by one, the investigation continued with pairs. All possible combinations were made and were compared to each other. These combinations and their Intercept variables are the following as shown in Table 1:

Table 1. The investigated pairs, their intercept values, estimates, and standard errors.

\begin{tabular}{cccc}
\hline Pairs & Intercept Levels of the Pairs & Estimate & Standard Error \\
\hline FoV \& Camera rotation & $45^{\circ} \&-15^{\circ}$ & $235.153 \mathrm{~s}$ & $10.828 \mathrm{~s}$ \\
FoV \& Contrast ratio & $45^{\circ} \& 1.5: 1$ & $142.204 \mathrm{~s}$ & $5.201 \mathrm{~s}$ \\
FoV \& Display device & $45^{\circ}$ \& desktop display & $189.449 \mathrm{~s}$ & $4.183 \mathrm{~s}$ \\
FoV \& Shadows & $45^{\circ} \&$ shadows on & $195.200 \mathrm{~s}$ & $5.424 \mathrm{~s}$ \\
Camera rotation \& Shadows & $-15^{\circ}$ \& shadows on & $233.400 \mathrm{~s}$ & $10.438 \mathrm{~s}$ \\
Camera rotation \& Display device & $-15^{\circ} \&$ desktop display & $223.473 \mathrm{~s}$ & $7.167 \mathrm{~s}$ \\
Camera rotation \& Contrast ratio & $-15^{\circ}$ \& 1.5:1 & $155.049 \mathrm{~s}$ & $22.122 \mathrm{~s}$ \\
Shadows \& Display device & shadows off \& desktop display & $184.162 \mathrm{~s}$ & $3.711 \mathrm{~s}$ \\
Shadows \& Contrast ratio & shadows off \& 1.5:1 & $145.195 \mathrm{~s}$ & $4.793 \mathrm{~s}$ \\
Display device \& Contrast ratio & desktop display \& 1.5:1 & $138.634 \mathrm{~s}$ & $3.802 \mathrm{~s}$ \\
\hline
\end{tabular}

As can be seen in Table 1, the pair of $45^{\circ} \mathrm{FoV} \&-15^{\circ}$ camera rotation has the largest estimate of seconds, while the pair of desktop display \& 1.5:1 contrast ratio and the desktop display have the smallest. If the pairs are looked at, it can also be suspected that when the $-15^{\circ}$ camera rotations are paired with another factor, the estimates become quite large. These estimates are the largest ones. Similarly, when the 1.5:1 contrast ratio is paired with another factor, the estimates decrease. These estimates are the smallest ones.

The significant pairs resulting from the comparison can be seen in Figure 3 in the form of $95 \%$ CIs. From this point onward, the following new abbreviations are used: ROT for camera rotation, CR for contrast ratio, DD for desktop display, GVR for the Gear VR, SH ON for turned on shadows, and lastly, SH OFF for turned off shadows. As illustrated in Figure 3, there are 75 pairs with significant decreases and increases in completion times. 23 pairs decrease test completion times significantly, while 52 increase them. The largest significant decrease is in the case of $75^{\circ} \mathrm{FoV}$ and $-45^{\circ}$ camera rotation, while the largest significant increase is in the case of the Gear VR and 7:1 contrast ratio. 


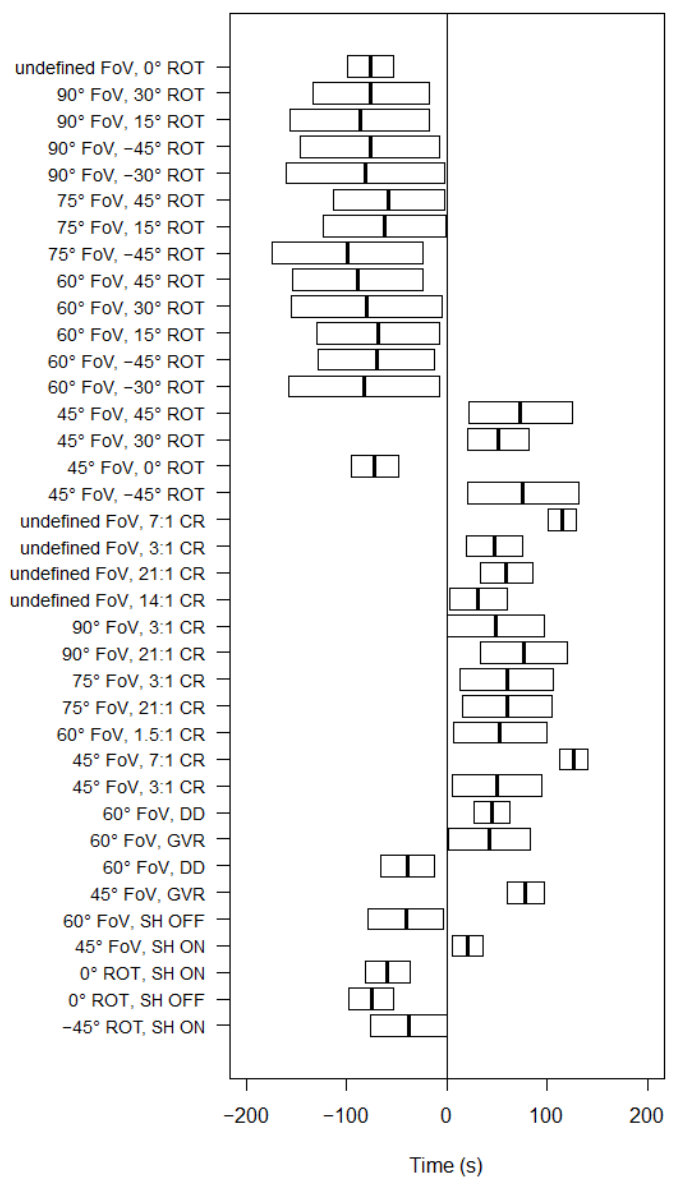

(a)

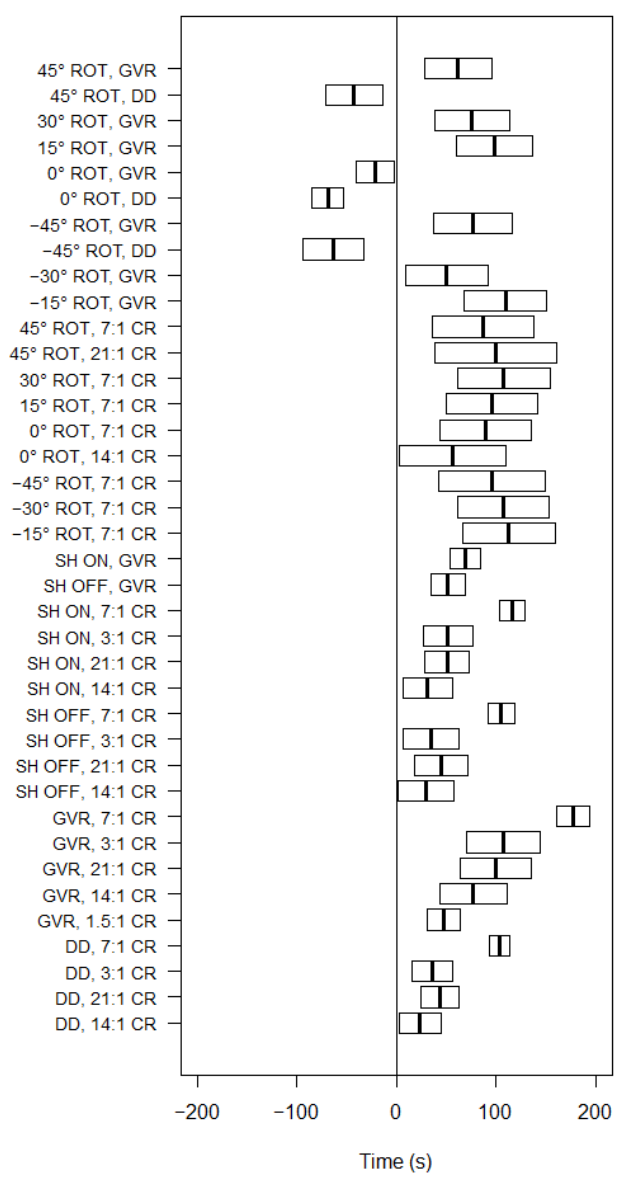

(b)

Figure 3. $95 \%$ CIs of each investigated significant pair of factors, graphically split into (a,b) for better readability.

Next, the interactions between all pairs of factors were assessed. To conserve space, only the significant interactions are shown in Table 2. Inside the "Estimate" column, the estimates of the Intercept variables are presented between brackets, respectively.

The data presented in Table 2 shows that the pair of FoV and camera rotation has the largest number of significant interactions: there are seven of them. Contrarily, the pairs of FoV \& Display device; Camera rotation \& Display device; Camera rotation \& Contrast ratio; and lastly, Contrast ratio \& Display device have only one significant interaction in them. The largest increase can be found in the case of $75^{\circ} \mathrm{FoV}$ and $0^{\circ}$ camera rotation, while the largest decrease exists in the case of $90^{\circ} \mathrm{FoV} \& 7: 1$ Contrast ratio with an estimate of $149.376 \mathrm{~s}$. It can also be observed in Table 2 that when the camera rotation is paired with an undefined FoV, the estimates of interactions significantly decrease. A similar phenomenon happens when it is paired with the Gear VR.

Also, pairs that do not have interactions exist in the model. These are the following: FoV \& Shadows; Camera rotation \& Shadows; Display device \& Shadows; and lastly, Contrast ratio \& Shadows. This means that every pair that has the factor of shadows in them, do not have significant interactions. 
Table 2. Significant interactions among variable pairs.

\begin{tabular}{ccccc}
\hline Pair & Interaction & Estimate & Standard Error & Significance \\
\hline & undefined \& $-45^{\circ}$ & $(235.153 \mathrm{~s})-116.335 \mathrm{~s}$ & $34.498 \mathrm{~s}$ & 0.000756 \\
& $60^{\circ} \& 0^{\circ}$ & $(235.153 \mathrm{~s})+87.491 \mathrm{~s}$ & $37.625 \mathrm{~s}$ & 0.020127 \\
& $75^{\circ} \& 0^{\circ}$ & $(235.153 \mathrm{~s})+113.522 \mathrm{~s}$ & $42.469 \mathrm{~s}$ & 0.007563 \\
FoV \& ROT & $90^{\circ} \& 0^{\circ}$ & $(235.153 \mathrm{~s})+106.576 \mathrm{~s}$ & $38.876 \mathrm{~s}$ & 0.006158 \\
& undefined \& $30^{\circ}$ & $(235.153 \mathrm{~s})-83.108 \mathrm{~s}$ & $20.514 \mathrm{~s}$ & $5.24 \times 10^{-5}$ \\
& $60^{\circ} \& 45^{\circ}$ & $(235.153 \mathrm{~s})-109.940 \mathrm{~s}$ & $50.618 \mathrm{~s}$ & 0.029947 \\
& undefined \& $45^{\circ}$ & $(235.153 \mathrm{~s})-100.112 \mathrm{~s}$ & $31.145 \mathrm{~s}$ & 0.001323 \\
\hline FoV \& Display device & undefined \& GVR & $(189.449 \mathrm{~s})-38.779 \mathrm{~s}$ & $12.773 \mathrm{~s}$ & 0.002420 \\
\hline & $60^{\circ} \& 21: 1$ & $(142.204 \mathrm{~s})-94.178 \mathrm{~s}$ & $39.031 \mathrm{~s}$ & 0.015900 \\
FoV \& CR & $60^{\circ} \& 7: 1$ & $(142.204 \mathrm{~s})-139.055 \mathrm{~s}$ & $32.592 \mathrm{~s}$ & $2.05 \times 10^{-5}$ \\
& $75^{\circ} \& 7: 1$ & $(142.204 \mathrm{~s})-122.968 \mathrm{~s}$ & $30.117 \mathrm{~s}$ & $4.58 \times 10^{-5}$ \\
\hline ROT \& Display device & $90^{\circ} \& 7: 1$ & $(142.204 \mathrm{~s})-149.376 \mathrm{~s}$ & $35.079 \mathrm{~s}$ & $2.13 \times 10^{-5}$ \\
\hline ROT \& CR & $0^{\circ} \& \mathrm{GVR}$ & $(223.473 \mathrm{~s})-61.777 \mathrm{~s}$ & $22.405 \mathrm{~s}$ & 0.005870 \\
\hline CR \& Display device & $30^{\circ} \& 21: 1$ & $(155.049 \mathrm{~s})-87.817 \mathrm{~s}$ & $43.652 \mathrm{~s}$ & 0.044300 \\
\hline
\end{tabular}

\subsection{The Effect of Factor Triplets}

The next step was to analyze the triplets of factors. Similar to before, all possible combinations of factors were created. These combinations and their Intercept levels are the following as shown in Table 3, while the significant pairs resulting from the comparison can be seen in Figure 4 in the form of $95 \%$ CIs.

As can be seen in Table 3, when the contrast ratio of 1.5:1 is present in the intercept levels, the estimates become smaller. Usually, when either the desktop display or the turned off shadows factor is in the intercept levels, the estimates also become smaller. However, when either the $45^{\circ} \mathrm{FoV}$ or the $-15^{\circ}$ camera rotation is beside them, the estimate increases. Therefore, it can be suspected from Table 3 , that the $45^{\circ} \mathrm{FoV}$ and $-15^{\circ}$ camera rotation can increase completion times when they are in a triplet.

According to the results, there are 179 significant differences when triplets are involved. There are 23 significant decreases in completion times, while the remaining 156 differences are significant increases. The largest significant decrease with an estimate of $-132.228 \mathrm{~s}$ is when $75^{\circ} \mathrm{FoV}$ and $-45^{\circ}$ camera rotation is used with turned on shadows ( $p$-value $=0.029173$ ), while the largest significant increase with an estimate of $420.88 \mathrm{~s}$ on average is when $75^{\circ} \mathrm{FoV}, 45^{\circ}$ camera rotation and $3: 1$ contrast ratio are used $(p$-value $=0.000768)$.

Table 3. The investigated triplets, their intercept values, estimates, and standard errors.

\begin{tabular}{cccc}
\hline Triplet & Intercept Levels of Triplets & Estimate & Standard Error \\
\hline FoV \& ROT \& Display device & $45^{\circ} \&-15^{\circ} \&$ DD & $216.759 \mathrm{~s}$ & $11.367 \mathrm{~s}$ \\
FoV \& ROT \& CR & $45^{\circ} \&-15^{\circ} \& 1.5: 1$ & $69.78 \mathrm{~s}$ & $55.89 \mathrm{~s}$ \\
FoV \& ROT \& Shadows & $45^{\circ} \&-15^{\circ} \&$ SH OFF & $230.278 \mathrm{~s}$ & $16.645 \mathrm{~s}$ \\
FoV \& Display device \& CR & $45^{\circ} \&$ DD \& 1.5:1 & $131.359 \mathrm{~s}$ & $5.647 \mathrm{~s}$ \\
FoV \& Display device \& Shadows & $45^{\circ}$ \& DD \& SH OFF & $182.441 \mathrm{~s}$ & $5.864 \mathrm{~s}$ \\
FoV \& CR \& Shadows & $45^{\circ}$ \& 1.5:1 \& SH OFF & $136.490 \mathrm{~s}$ & $7.134 \mathrm{~s}$ \\
ROT \& Display device \& CR & $-15^{\circ} \&$ DD \& 1.5:1 & $150.785 \mathrm{~s}$ & $22.378 \mathrm{~s}$ \\
ROT \& Display device \& Shadows & $-15^{\circ}$ \& DD \& SH OFF & $218.658 \mathrm{~s}$ & $10.867 \mathrm{~s}$ \\
ROT \& CR \& Shadows & $-15^{\circ} \& 1.5: 1$ \&H OFF & $152.512 \mathrm{~s}$ & $37.612 \mathrm{~s}$ \\
Display device \& CR \& Shadows & DD \& 1.5:1 \& SH OFF & $137.152 \mathrm{~s}$ & $5.238 \mathrm{~s}$ \\
\hline
\end{tabular}



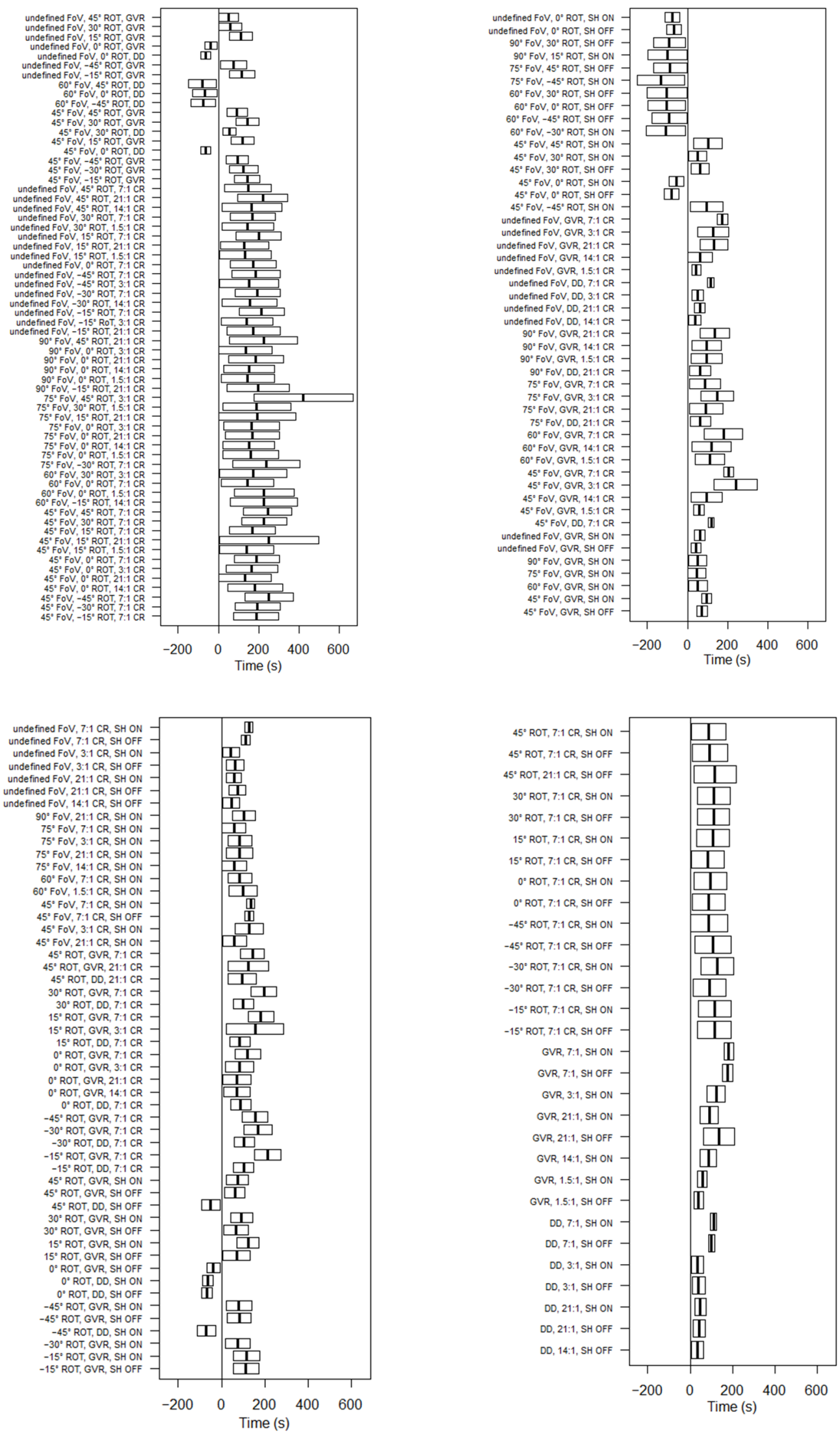

(a)

(b)

Figure 4. 95\% CIs of each investigated significant triplet of factors, graphically split into (a,b) for better readability. 
Afterward, the interaction among triplets was examined. Before assessing each triplet, the ANOVA variance analysis was used to identify which model is optimal out of three: regression models with only additive properties (I), regression models in which the interaction of pairs is allowed (II), and regression models in which the interaction of triplets is allowed (III). The results of this analysis are presented in Table 4 and the optimal models are also shown in it.

Table 4. Comparison of models ( $p$-values).

\begin{tabular}{ccccc}
\hline Variables & Model I, II & Model I, III & Model II, III & Optimal Model \\
\hline FoV \& ROT \& Display device & $1.442 \times 10^{-8}$ & $7.337 \times 10^{-6}$ & 0.9697 & II \\
FOV \& ROT \& CR & $1.639 \times 10^{-8}$ & 0.000325 & 0.8916 & II \\
FoV \& ROT \& Shadows & $4.022 \times 10^{-14}$ & $4.344 \times 10^{-10}$ & 0.4625 & II \\
FoV \& Display device \& CR & $4.528 \times 10^{-6}$ & 0.0001402 & 0.6667 & II \\
FoV \& Display device \& Shadows & 0.052120 & 0.52680 & 0.9770 & I \\
FoV \& CR \& Shadows & $1.095 \times 10^{-6}$ & $2.962 \times 10^{-5}$ & 0.2415 & II \\
ROT \& Display device \& CR & $1.503 \times 10^{-5}$ & 0.0008141 & 0.8482 & II \\
ROT \& Display device \& Shadows & $4.469 \times 10^{-5}$ & 0.004081 & 0.7247 & II \\
ROT \& CR \& Shadows & 0.00682 & 0.08343 & 0.704 & II \\
Display device \& CR \& Shadows & 0.261 & 0.5767 & 0.7253 & I \\
\hline
\end{tabular}

As can be seen in Table 4, when comparing model I and model II, 8 significant differences exist among them. This means that model II proved to be superior in 8 cases. In the remaining ones, the optimal model is the additive model (I) as there was no significant interaction found among the factors. When comparing model I and model III, 7 significant differences were found, but when comparing model II and model III, the latter did not prove to be better than the former.

Ultimately, model III is not better than model II. Therefore, this means that in 8 cases, model II is the most appropriate of all three models. Model I should be used in the case of the remaining 2 cases. In the end, according to the optimal models, there are 45 significant interactions among pairs of factors.

\subsection{The Effect of More than Three Factors}

In this section, the effect of more than three factors is analyzed. It should be noted that due to a large number of quartets and quintets, many of them contain small $(\leq 10)$ sample sizes due to the used randomization technique as was mentioned in Section 3. Therefore, the results presented in this subsection should be interpreted with caution.

As before, the models were compared to each other to find the optimal one. This means that during the investigation, every model (regression models with only additive properties (I), regression models in which the interaction of pairs is allowed (II), regression models in which the interaction of triplets is allowed (III), regression models in with the interaction of quartets are allowed (IV), and regression models in which the interaction of quintets are allowed (V)) was compared to each other with the ANOVA variance analysis.

Naturally, there were four models in the case of quartets and five in the case of quintets. In both cases, model II proved to be the best. Even if the interactions of at least variable triplets are permitted, no model is better than II.

\subsubsection{The Effect of Factor Quartets}

When investigating the effect of factor quartets all possible (864) combinations are made of them. Afterward, they were compared to each other. These combinations and their Intercept variables are the following as presented in Table 5. 
Table 5. The investigated quintets, their intercept values, estimates, and standard errors.

\begin{tabular}{cccc}
\hline Quartet & Intercept Levels of Quartets & Estimate & Standard Error \\
\hline FoV \& ROT \& Display device \& CR & $45^{\circ}$ FoV \& -15 ROT \& DD \& 1.5:1 CR & $69.780 \mathrm{~s}$ & $54.740 \mathrm{~s}$ \\
FoV \& ROT \& Display device \& S & $45^{\circ}$ FoV \& $-15^{\circ}$ ROT \& DD \& SH OFF & $213.313 \mathrm{~s}$ & $17.245 \mathrm{~s}$ \\
FoV \& ROT \& CR \& S & $45^{\circ}$ FoV \& -15 ROT \& 1.5:1 CR \& SH OFF & $69.780 \mathrm{~s}$ & $56.02 \mathrm{~s}$ \\
FoV \& Display device \& CR \& S & $45^{\circ}$ FoV \& DD \& 1.5:1 CR \& SH OFF & $125.094 \mathrm{~s}$ & $7.686 \mathrm{~s}$ \\
ROT \& Display device \& CR \& S & $-15^{\circ}$ ROT \& DD \& 1.5:1 CR \& SH OFF & $143.453 \mathrm{~s}$ & $38.817 \mathrm{~s}$ \\
\hline
\end{tabular}

According to the results, 230 significant quartets were found out of all possible 864 quartets. This means that $26.62 \%$ of the combinations are significant. However, only 6 combinations decrease the completion times significantly, while the remaining ones increase it. The greatest significant decrease is when $60^{\circ} \mathrm{FoV}, 45^{\circ}$ camera rotation, a desktop display is used without shadows.

\subsubsection{The Effect of Factor Quintets}

Lastly, the effect of factor quintets was investigated. As there were five factors, in the end, only one quintet could be examined: Camera FoV \& Camera rotation \& Display device \& Contrast ratio \& Shadows. Similarly, regression analysis was used for the investigation. The Intercept variable was $45^{\circ} \mathrm{FoV},-15^{\circ} \mathrm{ROT}$, DD, $1.5: 1 \mathrm{CR}$, and SH OFF with an estimate of $69.780 \mathrm{~s}$ on average and a standard error of 54.784 .

According to the results, 110 significant differences exist among quintets. It can also be seen that there are no significant decreases in completion times. The largest significant increase is when the quintet is $75^{\circ} \mathrm{FoV}, 45^{\circ} \mathrm{ROT}, \mathrm{DD}, 3: 1 \mathrm{CR}$, and SH ON. In this case, the increase is $420.880 \mathrm{~s}$ on average, which is approximately $7 \mathrm{~min}$. If the whole $\mathrm{CI}$ is looked at, the increase in completion times can reach approximately $10.5 \mathrm{~min}$. Contrarily, the smallest significant increase is when the quintet is $45^{\circ} \mathrm{FoV}, 0^{\circ} \mathrm{ROT}, \mathrm{GVR}, 1.5: 1 \mathrm{CR}$, and SH ON. The increase is $112.517 \mathrm{~s}$ on average which is almost $2 \mathrm{~min}$. While not significant, there are 11 quintets which could decrease the completion times. These can be seen in Figure 5.

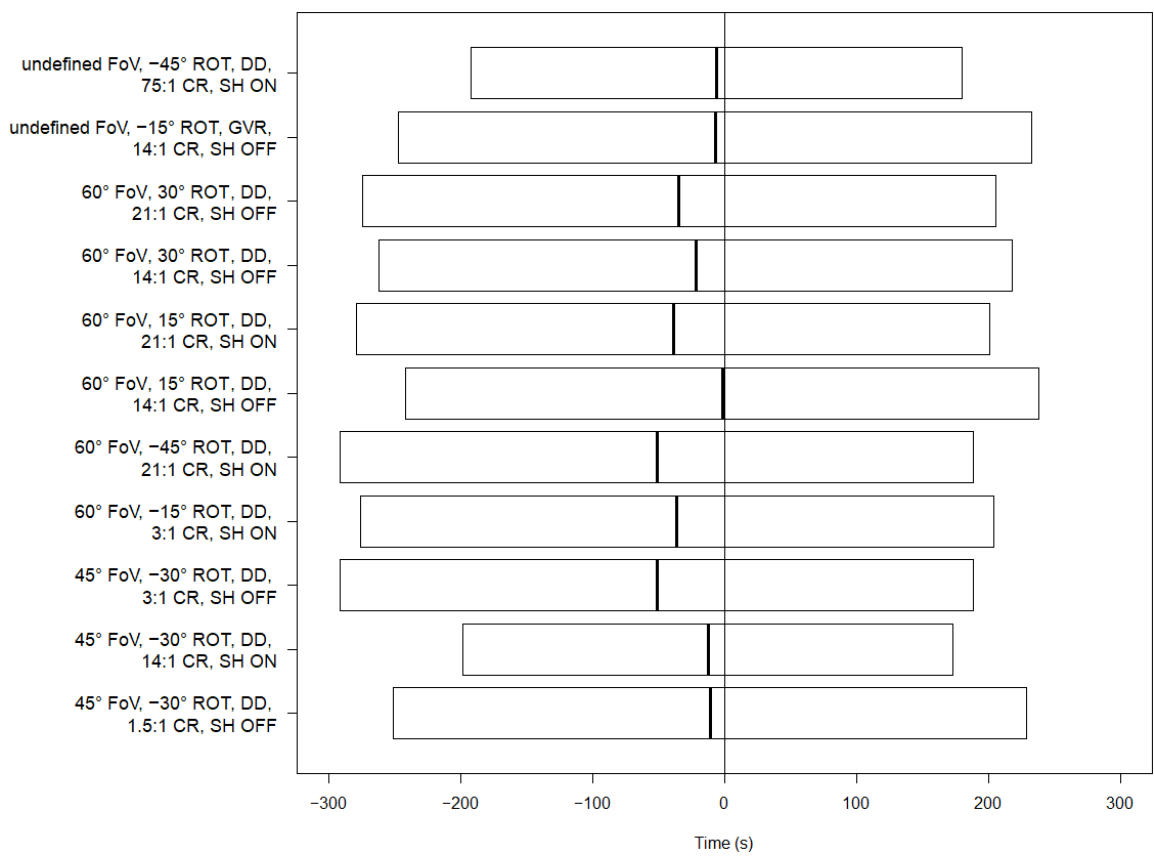

Figure 5. 95\% CIs of each factor quintet that can decrease completion times. 
While the quintets in Figure 5 can decrease completion times, they can also slightly increase them. As can be seen, most of these completion times are received using a desktop display, while there is only one with the use of the Gear VR.

Regarding significant interactions, 14 exist of them. Significant ones only occur among the pairs of FoV \& ROT; FoV \& CR; and ROT \& CR. The most significant interaction is in case of undefined FoV \& $30^{\circ}$ camera rotation $\left(p\right.$-value $\left.=6.01 \times 10^{-5}\right)$.

\section{Discussion}

The results show that the null hypotheses presented in Section 2 are rejected. This affirms the effect of the investigated factors, as was suspected. Therefore, this section is split into two subsections: the detected effects are presented in Section 5.1, while the importance of the results is detailed in Section 5.2.

\subsection{Detected Effects}

According to the results, every factor with the exception of the camera type has significant effects on completion times. Due to the results of the one-by-one analyses, the $60^{\circ} \mathrm{FoV}$, and the camera rotations of $0^{\circ}$ or $45^{\circ}$ significantly decrease the completion times, while the contrast ratios of 3:1, 7:1, 14:1, 21:1, the existence of shadows and the use of the Gear VR significantly increase them.

Naturally, more factors can be found inside virtual environments. Therefore, the investigation continued in pairs: there are 75 pairs with significant decreases and increases in completion times. 23 pairs decrease test completion times significantly, while 52 increase them. The largest significant decrease is in the case of $75^{\circ} \mathrm{FoV}$ and $-45^{\circ}$ camera rotation (-99.00 s avg.), while the largest significant increase is in the case of the Gear VR and 7:1 contrast ratio (177.05 s avg.). The next two largest significant decreases are in the cases of $60^{\circ} \mathrm{FoV}$ and $45^{\circ}$ camera rotation (-88.83 s avg.) as well as $90^{\circ} \mathrm{FoV}$ and $15^{\circ}$ camera rotation ( $-86.56 \mathrm{~s}$ avg.), while the next two largest significant increases are in the cases of $45^{\circ} \mathrm{FoV}$ and 7:1 contrast ratio (125.95 s avg.) as well as shadows on and 7:1 contrast ratio (116.17 s avg.). As can be seen, if the pair consists of a 7:1 contrast ratio, the completion times are greatly increased.

The next step was to investigate triplets of factors. There are 23 significant decreases in completion times, while the remaining 156 differences are significant increases. The largest significant decrease is when $75^{\circ} \mathrm{FoV}$ and $-45^{\circ}$ camera rotation is used with turned on shadows (-132.22 s avg.), while the largest significant increase is when $75^{\circ} \mathrm{FoV}, 45^{\circ} \mathrm{camera}$ rotation, and 3:1 contrast ratio are used (420.88 s avg.). When triplets are analyzed, the model in which the interaction of pairs is allowed proved to be the best.

Similar phenomena occurred in the case of factor quartets and quintets: the model that allowed the interaction of pairs proved to be the best. When investigation quartets, only 6 combinations decrease the completion times significantly, while the remaining ones increase it. The greatest significant decrease is when $60^{\circ} \mathrm{FoV}, 45^{\circ}$ camera rotation a desktop display is used without shadows. ( $-106.29 \mathrm{~s}$ avg.) The remaining ones are:

- $\quad 45^{\circ} \mathrm{FoV}, 0^{\circ}$ camera rotation, desktop display, shadows turned off $(-70.60 \mathrm{~s}$ avg.)

- $\quad$ undefined $\mathrm{FoV}, 0^{\circ}$ camera rotation, desktop display, shadows turned on $(-67.37 \mathrm{~s}$ avg.)

- $\quad$ undefined $\mathrm{FoV}, 0^{\circ}$ camera rotation, desktop display, shadows turned off ( $-52.38 \mathrm{~s}$ avg.)

- $45^{\circ} \mathrm{FoV}, 0^{\circ}$ camera rotation, desktop display, shadows turned on ( $-48.23 \mathrm{~s}$ avg.)

- $\quad$ undefined FoV, $0^{\circ}$ camera rotation, Gear VR, shadows turned off $(-43.99 \mathrm{~s}$ avg.)

According to the factors inside the quartets, a larger possibility exists for a quartet to significantly decrease completion times when the camera is not rotated and when a desktop display is used. The three quartets with the largest significant increases are:

- $\quad 75^{\circ} \mathrm{FoV}, 45^{\circ}$ camera rotation, desktop display, and 3:1 contrast ratio (420.88 s avg.)

- $\quad 75^{\circ} \mathrm{FoV}, 45^{\circ}$ camera rotation, 3:1 contrast ratio, and shadows on (420.88 s avg.)

- $\quad 75^{\circ} \mathrm{FoV}, 15^{\circ}$ camera rotation, desktop display, and 21:1 contrast ratio (356.08 s avg.) 
As can be seen, the first two produced the same completion times. The authors suspect that perhaps, they are part of the same quintet. Also, it can be seen that the largest significant increase in the case of triplets is equal to this time.

In the case of quintets, the previous suspicion of the authors proved to be true: the increase in time in case of the largest significant quintet $\left(75^{\circ} \mathrm{FoV}, 45^{\circ}\right.$ camera rotation, desktop display, 3:1 contrast ratio, and shadows on) is $420.88 \mathrm{~s}$ on average as well. This is also equal to the largest increase among triplets. Therefore, based on these facts, the parameters of $75^{\circ} \mathrm{FoV}, 45^{\circ}$ camera rotation, and a 3:1 contrast ratio are required for the largest increase in completion times.

After the largest significant increase, the next two quintets are the following: $60^{\circ} \mathrm{FoV}$, $-15^{\circ}$ camera rotation, desktop display, 3:1 contrast ratio and no shadows (413.72 s avg.), as well as $45^{\circ} \mathrm{FoV}, 30^{\circ}$ camera rotation, Gear VR, 7:1 contrast ratio and shadows on (406.28 s avg.). There are no significant decreases in the case of quintets.

To assess the significance of each factor in every significant combination, their occurrences are examined. This can be seen in Table 6 .

Table 6. Number of occurrences of each factor in significant combinations. The largest occurrence per factor is denoted by *.

\begin{tabular}{|c|c|c|c|c|}
\hline Factors & Pairs & Triplets & Quartets & Quintets \\
\hline undefined FoV & $11 *$ & $34 *$ & $76 *$ & $44^{*}$ \\
\hline $45^{\circ} \mathrm{FoV}$ & 8 & 27 & 57 & 36 \\
\hline $60^{\circ} \mathrm{FoV}$ & 9 & 17 & 22 & 11 \\
\hline $75^{\circ} \mathrm{FoV}$ & 5 & 19 & 25 & 10 \\
\hline $90^{\circ} \mathrm{FoV}$ & 6 & 14 & 18 & 10 \\
\hline$-45^{\circ} \mathrm{ROT}$ & $4^{*}$ & 6 & 8 & 5 \\
\hline$-30^{\circ} \mathrm{ROT}$ & 2 & 4 & 9 & 6 \\
\hline$-15^{\circ} \mathrm{ROT}$ & 0 & 5 & 15 & 9 \\
\hline $0^{\circ} \mathrm{ROT}$ & 3 & 19 * & $36 *$ & $24 *$ \\
\hline $15^{\circ} \mathrm{ROT}$ & 3 & 6 & 15 & 9 \\
\hline $30^{\circ} \mathrm{ROT}$ & 3 & 9 & 13 & 7 \\
\hline $45^{\circ} \mathrm{ROT}$ & 3 & 7 & 12 & 7 \\
\hline DD & 8 & 30 & 66 & 52 \\
\hline GVR & $17^{*}$ & $69 *$ & $99 *$ & $59 *$ \\
\hline 1.5:1 CR & 2 & 14 & 30 & 14 \\
\hline $3: 1 \mathrm{CR}$ & 8 & 21 & 32 & 12 \\
\hline 7:1 CR & $13^{*}$ & $58 *$ & $93 *$ & 54 * \\
\hline 14:1 CR & 6 & 16 & 26 & 14 \\
\hline 21:1 CR & 8 & 29 & 34 & 17 \\
\hline SH OFF & 2 & 38 & 68 & 65 \\
\hline SH ON & $8 *$ & $49 *$ & $97 *$ & $67 *$ \\
\hline
\end{tabular}

According to the occurrences presented in Table 6, it can be stated undefined FoV, $0^{\circ}$ camera rotation, Gear VR, 7:1 contrast ratio, and turned-on shadows are the factors that occur in the most significant combinations. Therefore, these are the factors that often and significantly influence completion times. Out of these most occurring factors, only the $0^{\circ}$ camera rotation is the one that can significantly decrease completion times by itself, while the other significantly increase them by themselves.

\subsection{The Importance of the Results}

These spatial ability measuring tests are part of the curriculum of engineering studies, and some universities even have these tests as part of their entrance exams. Since these tests are quite important and the world is transitioning into a digital age, a virtual realitybased version was created as part of this study. Although our participants had "infinite" minutes to complete these spatial ability measuring tests, when paper-based tests are done, 
deadlines are included. Since virtual reality-based versions of these tests are appearing in the modern age, these tests may be taken in virtual environments. This would mean that deadlines should be included in this variant as well.

As virtual environments are made up of various components, the perceptions of users can be influenced. According to the results, the optimal test deadline can vary among various virtual environments, depending on their various factors: the FoV, camera rotation, contrast ratio, the existence of shadows, and even the display devices themselves can significantly affect completion times. Thus, when these tests are taken inside virtual environments, the optimal test completion deadline has to be carefully selected by the test organization committees.

Since no virtual environment is made up of one factor, six were investigated in this study. Out of six, five have significant effects on completion times. According to the results, while certain pairs of factors significantly interact with each other, the test completion times are significantly increased when factor quintets are investigated. In the end, it can be concluded that test completion times are significantly increased by these factors in virtual environments. Naturally, every increase depends on the parameters of virtual environments, but in the worst case, 7-10.5 min should be added to the test deadlines when these tests are taken inside virtual environments.

\section{Conclusions}

Virtual reality systems are made up of various components, such as the virtual reality engine, its software (and database), I/O devices, tasks, and humans. All are equally important in the system. As can be seen, the completion times are influenced by several of these components. Consequently, human-computer interaction is affected by these components as well.

While the virtual camera type does not significantly affect completion times, the combination of $75^{\circ} \mathrm{FoV}, 45^{\circ}$ camera rotation, and 3:1 contrast ratio has the largest increase in completion times with an estimate of $420.88 \mathrm{~s}$. This fact is also true when this combination is inside a quartet or a quintet of variables. Consequently, significant decreases in completion times exist up to variable quartets. In this case, the largest is $-106.29 \mathrm{~s}$ on average. The significance in the case of decreasing completion times disappears when variable quintets are examined. Although 11 quintets can decrease completion times, they are not significant.

Besides these facts, it can also be concluded that an undefined $\mathrm{FoV}$, a $0^{\circ}$ camera rotation, the Gear VR, a 7:1 contrast ratio, and turned-on shadows are the factors that occur in most significant combinations. These are the factors that often and significantly influence completion times. Naturally, the findings could be used in other engineering applications as well. For example, when designing $3 \mathrm{D}$ objects in virtual environments, the workflow could also be made easier with these optimal parameters as the users could see spatial relations more clearly, and thus, faster.

However, it is important to note that since paper-based versions of these tests are part of the curriculum of engineering studies, deadlines have to be given to the students. Based on the results presented in this study, if/when these spatial ability tests are taken in virtual environments, the deadlines can be set more precisely by the test examination committee in the future. This fact is important because the required time for the tests can vary due to the influences of display devices as well as the parameters of virtual environments.

Author Contributions: Conceptualization, T.G.; methodology, T.G. and É.O.-M.; software, T.G.; validation, T.G. and É.O.-M.; formal analysis, T.G.; investigation, T.G.; resources, T.G. and E.P.; data curation, T.G., É.O.-M. and C.S.-L.; writing-original draft preparation, T.G.; writing-review and editing, T.G., É.O.-M., C.S.-L. and E.P.; visualization, T.G.; supervision, T.G.; project administration, T.G. All authors have read and agreed to the published version of the manuscript.

Funding: This research received no external funding. 
Institutional Review Board Statement: Ethical review and approval were waived for this study, due to the fact that informed oral consent was received from the participants, and they cannot be identified based on the information that was gathered.

Informed Consent Statement: Informed oral consent was obtained from all subjects involved in the study.

Data Availability Statement: The data presented in this study are available on request from the corresponding author.

Acknowledgments: This research is supported by the ÚNKP-21-4 New National Excellence Program of the Ministry for Innovation and Technology from the source of the National Research, Development, and Innovation Fund. The authors would also like to thank Mónika Szeles for her help in developing the application as well as Lóránt Horváth for his help in the creation of objects for the MCT test type. Last, but not least, the authors would like to thank everyone who helped by testing the spatial ability application.

Conflicts of Interest: The authors declare no conflict of interest.

\section{References}

1. Ghiselli, E.E. The validity of aptitude tests in personnel selection. Pers. Psychol. 1973, 26, 461-477. [CrossRef]

2. Miller, C.L. Enhancing visual literacy of engineering students through the use of real and computer generated models. Eng. Des. Graph. J. 1992, 56, 27-38.

3. Miller, C.L.; Bertoline, G.R. Spatial visualization research and theories: Their importance in the development of an engineering and technical design graphics curriculum model. Eng. Des. Graph. J. 1991, 55, 5-14.

4. Vandenberg, S.G.; Kuse, A.R. Mental rotations, a group test of three-dimensional spatial visualization. Percept. Motor. Skill. 1978, 47, 599-604. [CrossRef]

5. College Entrance Examination Board (CEEB): Special Aptitude Test in Spatial Relations, Developed by the College Entrance Examination Board; CEEB: New York, NY, USA, 1939.

6. Guay, R.B. Purdue Spatial Visualization Test_Visualization of Rotations; Purdue Research Foundation: West Lafayette, IN, USA, 1977.

7. Rizzo, A.A.; Buckwalter, J.G.; Neumann, U.; Kesselman, C.; Thiébaux, M.; Larson, P.; van Rooyen, A. The virtual reality mental rotation spatial skills project. Cyberpsychol. Behav. 1998, 1, 113-119. [CrossRef]

8. Hercegfi, K.; Komlódi, A.; Szabó, B.; Köles, M.; Lógó, E.; Hámornik, B.P.; Rózsa, G. Experiences of virtual desktop collaboration experiments. In Proceedings of the 2015 6th IEEE International Conference on Cognitive Infocommunications (CogInfoCom), Gyor, Hungary, 19-21 October 2015; pp. 375-379. [CrossRef]

9. Molina-Carmona, R.; Pertegal-Felices, M.L.; Jimeno-Morenilla, A.; Mora-Mora, H. Virtual Reality Learning Activities for Multimedia Students to Enhance Spatial Ability. Sustainability 2018, 10, 1074. [CrossRef]

10. Gómez-Tone, H.C.; Martin-Gutierrez, J.; Valencia Anci, L.; Mora Luis, C.E. International Comparative Pilot Study of Spatial Skill Development in Engineering Students through Autonomous Augmented Reality-Based Training. Symmetry 2020, 12,1401 [CrossRef]

11. Tóth, R.; Zichar, M.; Hoffmann, M. Gamified Mental Cutting Test for enhancing spatial skills. In Proceedings of the 2020 11th IEEE International Conference on Cognitive Infocommunications (CogInfoCom), Mariehamn, Finland, 23-25 September 2020; pp. 299-304. [CrossRef]

12. Tóth, R.; Zichar, M.; Hoffmann, M. Improving and Measuring Spatial Skills with Augmented Reality and Gamification. In Proceedings of the International Conference on Geometry and Graphics, Hong Kong, China, 6-8 December 2021; Springer: Cham, Swizterland, 2021; pp. 755-764. [CrossRef]

13. Burdea, G.C.; Coiffet, P. Virtual Reality Technology; John Wiley: Hoboken, NJ, USA, 2003.

14. Capanema, I.F.; Santos Garcia, F.L.; Tissiani, G. Implications of Virtual Reality in Education. Virtual Reality in Education: Online Survey. 2001.

15. Zhou, X.; Jin, Y.; Jia, L.; Xue, C. Study on Hand-Eye Cordination Area with Bare-Hand Click Interaction in Virtual Reality. Appl. Sci. 2021, 11, 6146. [CrossRef]

16. Sutcliffe, A.G.; Poullis, C.; Gregoriades, A.; Katsouri, I.; Tzanavari, A.; Herakleous, K. Reflecting on the Design Process for Virtual Reality Applications. Int. J. Hum. Comput. Interact. 2019, 35, 168-179. [CrossRef]

17. Cutmore, T.R.; Hine, T.J.; Maberly, K.J.; Langford, N.M.; Hawgood, G. Cognitive and gender factors influencing navigation in a virtual environment. Int. J. Hum. Comput. Study 2000, 53, 223-249. [CrossRef]

18. Cidota, M.A.; Clifford, R.M.S.; Lukosch, S.G.; Billinghurst, M. Using Visual Effects to Facilitate Depth Perception for Spatial Tasks in Virtual and Augmented Reality. In Proceedings of the 2016 IEEE International Symposium on Mixed and Augmented Reality (ISMAR-Adjunct), Merida, Mexico, 19-23 September 2016; pp. 172-177. [CrossRef]

19. Gerig, N.; Mayo, J.; Baur, K.; Wittmann, F.; Riener, R.; Wolf, P. Missing depth cues in virtual reality limit performance and quality of three dimensional reaching movements. PLoS ONE 2018, 13, e0189275. [CrossRef] [PubMed]

20. Guzsvinecz, T.; Orbán-Mihálykó, É.; Perge, E.; Sik-Lányi, C. Analyzing the spatial skills of university students with a Virtual Reality application using a desktop display and the Gear VR. Acta Polytech. Hung. 2020, 17, 35-56. [CrossRef] 
21. Guzsvinecz, T.; Orbán-Mihálykó, É.; Sik-Lányi, C.; Perge, E. Investigation of spatial ability test completion times in virtual reality using a desktop display and the Gear VR. Virtual Real. 2021, 1-14. [CrossRef]

22. Armbrüster, C.; Wolter, M.; Kuhlen, T.; Spijkers, W.; Fimm, B. Depth perception in virtual reality: Distance estimations in peri-and extrapersonal space. Cyberpsychol. Behav. 2008, 11, 9-15. [CrossRef]

23. Renner, R.S.; Velichkovsky, B.M.; Helmert, J.R. The perception of egocentric distances in virtual environments-a review. ACM Comput. Surv. 2013, 46, 1-40. [CrossRef]

24. Field, B.W. A course in spatial visualisation. J. Geom. Graph. 1999, 3, 201-209.

25. Safadel, P.; White, D. Effectiveness of Computer-Generated Virtual Reality (VR) in Learning and Teaching Environments with Spatial Frameworks. Appl. Sci. 2020, 10, 5438. [CrossRef]

26. Gómez-Tone, H.C.; Martin-Gutierrez, J.; Bustamante-Escapa, J.; Bustamante-Escapa, P. Spatial Skills and Perceptions of Space: Representing 2D Drawings as 3D Drawings inside Immersive Virtual Reality. Appl. Sci. 2021, 11, 1475. [CrossRef]

27. Dünser, A.; Steinbügl, K.; Kaufmann, H.; Glück, J. Virtual and augmented reality as spatial ability training tools. In Proceedings of the 7th ACM SIGCHI New Zealand Chapter's International Conference on Computer-Human Interaction: Design Centered HCI, New York, NY, USA, 6-7 July 2006; pp. 125-132. [CrossRef]

28. Parsons, T.D.; Larson, P.; Kratz, K.; Thiebaux, M.; Bluestein, B.; Buckwalter, J.G.; Rizzo, A.A. Sex differences in mental rotation and spatial rotation in a virtual environment. Neuropsychologia 2004, 42, 555-562. [CrossRef]

29. Katona, J. A Review of Human-Computer Interaction and Virtual Reality Research Fields in Cognitive InfoCommunications. Appl. Sci. 2021, 11, 2646. [CrossRef]

30. Baranyi, P.; Csapo, A.; Sallai, G. Cognitive Infocommunications (CogInfoCom); Springer: Berlin/Heidelberg, Germany, 2015. [CrossRef]

31. Kovari, A.; Katona, J.; Costescu, C. Quantitative Analysis of Relationship Between Visual Attention and Eye-Hand Coordination. Acta Polytech. Hung. 2020, 17, 77-95. [CrossRef]

32. Katona, J. Clean and Dirty Code Comprehension by Eye-tracking Based Evaluation using GP3 Eye Tracker. Acta Polytech. Hung. 2021, 18, 79-99. [CrossRef]

33. Katona, J. Analyse the Readability of LINQ Code using an Eye-Tracking-based Evaluation. Acta Polytech. Hung. 2021, 18, 193-215 [CrossRef]

34. Katona, J.; Ujbanyi, T.; Sziladi, G.; Kovari, A. Examine the effect of different web-based media on human brain waves. In Proceedings of the 2017 8th IEEE International Conference on Cognitive Infocommunications (CogInfoCom), Debrecen, Hungary, 11-14 September 2017; pp. 407-412. [CrossRef]

35. Macik, M. Cognitive aspects of spatial orientation. Acta Polytech. Hung. 2018, 15, 149-167. [CrossRef]

36. Guzsvinecz, T.; Sik-Lanyi, C.; Orban-Mihalyko, E.; Perge, E. The Influence of Display Parameters and Display Devices over Spatial Ability Test Answers in Virtual Reality Environments. Appl. Sci. 2020, 10, 526. [CrossRef]

37. Chang, J.S.K.; Yeboah, G.; Doucette, A.; Clifton, P.; Nitsche, M.; Welsh, T.; Mazalek, A. Evaluating the effect of tangible virtual reality on spatial perspective taking ability. In Proceedings of the 5th Symposium on Spatial User Interaction, Brighton, UK, 16-17 October 2017; pp. 68-77. [CrossRef]

38. Guzsvinecz, T.; Szeles, M.; Perge, E.; Sik-Lanyi, C. Preparing spatial ability tests in a virtual reality application. In Proceedings of the 2019 10th IEEE International Conference on Cognitive Infocommunications (CogInfoCom), Naples, Italy, 23-25 October 2019; pp. 363-368. [CrossRef]

39. Gear VR SM-R322 Support \& Manual I Samsung Business. Available online: https://www.samsung.com/us/business/support/ owners/product/gear-vr-sm-r322/ (accessed on 8 October 2021).

40. Samsung Galaxy S6 Edge Plus-The Official Samsung Galaxy Site. Available online: https://www.samsung.com/global/galaxy/ galaxy-s6-edge-plus/ (accessed on 8 October 2021).

41. Heinrich, V. A Spatial Visualization Test for Selecting Engineering Students. Master's Thesis, The Ohio State University, Columbus, OH, USA, 1988.

42. LG LED Monitor 20M37A / 19.5 LG LED Monitor-LG Electronics UK. Available online: https://www.lg.com/uk/monitors/lg20M37A (accessed on 8 October 2021).

43. R: The R Project for Statistical Computing. Available online: https://www.r-project.org/ (accessed on 8 October 2021).

44. Walpole, R.E.; Myers, R.H.; Myers, S.L.; Ye, K. Probability E Statistics for Engineers \& Scientists; Pearson Prentice Hall: Hoboken, NJ, USA, 2011. 